\title{
Decontamination of Gilson ${ }^{\circledR}$ Pipettes Using High Intensity UV LED
}

info@phoseon.com I www.phoseon.com/life-sciences

For reprint orders, please contact: reprints@futuremedicine.com

\section{BACKGROUND}

Having clean pipettes is a consistent need in any laboratory. Current methods of cleaning, however, are not without downfalls. The process is often time-consuming and utilizes expensive chemicals that can leave residue and eventually cause corrosion. Thus, laboratories are in need of a quick and cost-effective way to decontaminate their pipettes.

\section{CONCLUSION}

Achieved complete inactivation of RNaseA on white shafts of Gilson ${ }^{\circledast}$ pipettes using Phoseon's KeyPro ${ }^{\text {TM }}$ UV LED Decontamination Instrument. Shafts suspended over reflector tray and exposed to two $0.5 \mathrm{~mm} / \mathrm{sec}$ scans (4 minute 54 second per scan) with $80 \% 275 \mathrm{~nm}$ intensity and $90 \% 365 \mathrm{~nm}$ intensity.

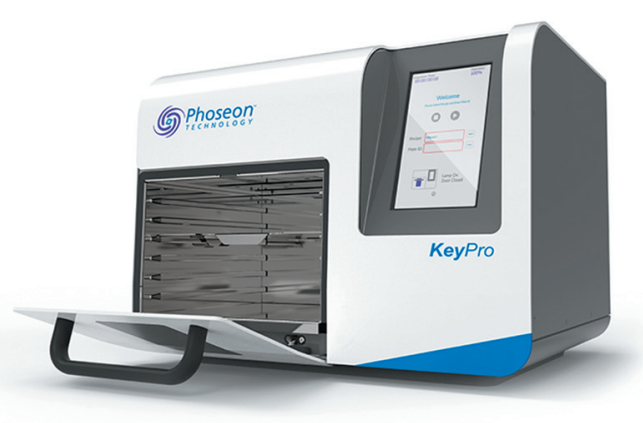

\section{METHODS}

Two shafts, one from a P200 and one from a P20 Gilson pipette, were soaked in 0.02u/mL RNaseA-doped water for 10 minutes. A total of $90 \mathrm{~mL}$ of doped water was prepared and split into two $50 \mathrm{~mL}$ graduated cylinders for soaking. Once dry, one shaft was exposed to a scanning UV LED source (KeyPro ${ }^{\text {TM }}$, a decontamination instrument from Phoseon Technology). Treatment shaft was set on the reflector system (suspended over a curved piece of reflective aluminum) and placed as close to the window as possible (tray placed at $32 \mathrm{~mm}$ mark). It was then exposed twice in KeyPro with $0.5 \mathrm{~mm} / \mathrm{sec}$ scan speed (4 minute 54 second total per scan) at $80 \% 275 \mathrm{~nm}$ intensity $\left(1.6 \mathrm{~W} / \mathrm{cm}^{2}\right.$ at the window) and $90 \% 365 \mathrm{~nm}$ intensity $\left(900 \mathrm{~mW} / \mathrm{cm}^{2}\right.$ at the window). Making sure the shaft was rotated between passes. Both shafts subsequently soaked in $\sim 25 \mathrm{ml}$ of NF H2O for 30 minutes for resuspension. Resuspension water then assayed in triplicate (one sample each from the top, middle, and bottom of the vessel). RNaseA activity measured via fluorimetry (Gemini XPS) using the RNaseAlert assay (IDT).

\section{RESULTS}

Complete inactivation of RNaseA on white shafts after two 4 minute 54 second passes in KeyPro ${ }^{\text {TM }}$, using reflector system with $80 \% 275 \mathrm{~nm}$ intensity and $90 \% 365 \mathrm{~nm}$ intensity. This was confirmed over three separate experiments (with treatment groups being sampled in triplicate each time). Below is a representative example from one of the three experiments.



Figure 1



Figure 2 